\title{
Service use patterns and mental health symptoms among adolescents exposed to multiple types of trauma
}

Gillian C. McChesney

Gary Adamson

Mark Shevlin

Gillian C. McChesney (corresponding author)

Room MB205

University of Ulster,

Northland Road,

Londonderry, 


\title{
Northern Ireland,
}

\section{BT48 7JL}

Email: mcchesney-g1@email.ulster.ac.uk

Tel: +442871 885129

\section{G. Adamson M. Shevlin}

University of Ulster,

Northland Road,

Londonderry,

Northern Ireland,

BT48 7JL

Email: g.adamson@ulster.ac.uk

\section{m.shevlin@ulster.ac.uk}

\begin{abstract}
Few studies have explored how different trauma experiences influence service use. This study explores patterns of service use amongst 6,483 adolescents aged between 13 and 18, and examines if such patterns are associated with trauma profiles, demographic variables, and mental health disorders. Data from the National Comorbidity Survey - Adolescent Supplement (NCS-A) were used. A latent class analysis identified four adolescent trauma sub-groups: 'high risk', 'sexual risk' 'non-sexual risk', and 'low risk'. Regression analysis was used to explore the relationship between service use, trauma classes, and mental health outcomes. Significant relationships were found between service use, trauma sub-groups, demographics and mental health outcomes. Despite the effectiveness of mental health services, only a minority of adolescents exposed to different traumas use such resources. However, this study may go some way towards providing an understanding of the trauma backgrounds, demographic predictors and mental health disorders associated with service use.
\end{abstract}




\section{Keywords}

Adolescence, Mental health, Trauma, Service Use

\section{Introduction}

Over the last 3 decades usage rates for mental health services have been gradually increasing. For example, in the United States in 1987 less than one person in every hundred (.73) received outpatient treatment for depression, increasing in 1997 to 2.33 (Olfson, et al., 2002), in 1998 to 2.37, and 2.88 in 2007 (Marcus \& Olfson, 2010). That said, despite these increases, some have concluded that the uptake of mental health services remains relatively low. The efficacy and availability of mental health services aimed at treating adolescents has been well documented, with better outcomes found for those who are treated against those who go untreated (Weisz \& Kazdin, 2010). However, despite their effectiveness and availability, evidence suggests that only as few as a third of adolescents with mental health disorders receive any form of treatment (Merikangas, et al., 2011). And for those who begin appropriate treatment, high levels of missed appointments and therapy terminated prematurely, represent significant barriers to the efficacy of such services (Gearing, Schwalbe, \& Short, 2012; Gopalan, et al., 2010). For example, in a sample of over 500 ethnically diverse children exposed to trauma, premature therapy termination was found to be significantly high, particularly amongst African-Americans (Fraynt, et al, 2014). For those who do not use mental health services, evidence has consistently shown 'attitudes' to be one of the more significant barriers in preventing them from doing so (Mackenzie, et al., 2013). Negative attitudes towards mental health services have been found to be significantly higher among young adults (15-24 years), with $35 \%$ and $25 \%$ of younger Americans and Canadians respectively expressing such views (Jagdeo, et al., 2009).

In the case of physical disorders it is widely accepted that the population can benefit from programmes directed at increasing knowledge of symptoms, interventions and treatments. Despite this, improving negative attitudes towards mental health disorders and treatments has received less attention. Research has shown that it is possible to improve such attitudes about mental health disorders using 'mental health literacy' programmes, aimed at different cohorts (Jorm, 2012). For adolescent populations school 
programmes have proved effective, with an increase in recognising 'primary health care' as a suitable resource, with females and older adolescents demonstrating lower levels of negativity (Skre, et al., 2013).

In addition to such 'mental health literacy' programmes, there is agreement that usage rates could be improved if mental health services were to move away from the more traditional psychiatric services provided by institutions to modern, community-based forms of treatment (de Almeida \& Killaspy, 2011). This shift would make services more accessible to all (Killaspy, 2007), would help protect human rights and prevent stigmatization of using such services (Thornicroft \& Tansella, 2003), and would, on the whole, be more cost effective (Roberts, Cumming, \& Nelson, 2005). While all these are essential to providing modern mental health services, of perhaps greater importance are the outcomes such a shift would have for service users, with evidence showing adherence to treatment, symptom improvement, and better subjective quality of life (Bond, et al., 2001).

Mental health services aimed at adolescents need to be considered differently than those for adults due to their unique developmental issues, differences in beliefs and values, and influences exerted on them by their peers (Winters, 1999). With this in mind resources available for adolescents, as with those for adults, fall into two main categories; psychosocial and pharmacological (US Department of Health and Human Services, 1999). Psychosocial services can include treatment by mental health professionals, such as psychotherapy. Pharmacological services provide appropriate disorder-specific medications (e.g. antidepressants, anti-psychotics), and can be offered separately or as part of a psychosocial combined programme. Adolescents also have access to a range of service types in addition to the traditional mental health treatments. It has long been recognised that schools play a key role in the recognition and treatment of mental disorders amongst children and adolescents, (Hoagwood \& Erwin, 1997). A role also reflected in past service use rates for children, with $70 \%$ of those who have made use of mental health services doing so within schools (Burns, et al., 1995). Burns et al (1995) also showed that of those using mental health services $40 \%$ used mental health specialty services (e.g. seeing a psychiatrist), and just $4 \%$ used another service type available to adolescents; juvenile justice services. U.S adolescents who have mental disorders (Grisso, 2008) and extensive trauma histories (Ford \& Blaustein, 2013) now make up a significant proportion of juvenile offenders, resulting in mental health services being offered within the juvenile justice 
system. However, the presence of such a range of resources is immaterial if only a third of adolescents with mental health issues access them (Merikangas, et al., 2010) and at usage rates as low as those found in adult populations (Wang, et al., 2005). It is therefore vital that studies examine not only rates of service use, but also patterns of utilisation; asking what is it that causes those in the adolescent population to seek help in the first place.

There is an increasing amount of research that suggests trauma exposure is all too common amongst children and adolescents (Fairbank, 2008), with repeated exposure to single and multiple traumas highly prevalent (Finkelhor, Ormrod, \& Turner, 2007; Ford, Elhai, Connor, \& Frueh, 2010). Common trauma experiences in adolescence include the death of a loved one, threats of violence and witnessing injury and death (Briggs, et al., 2013; Shevlin \& Elklit, 2008). Over the decades research has shown that adolescent trauma holds its own specific risks for poor psychological outcomes, with various sequelae such as depression, personality disorders and PTSD identified (Mullen, et al, 1988; Gibb, Chelminski, \& Zimmerman, 2007; Carr \& Francis, 2009; Green, et al., 2010; Guadiano \& Zimmerman, 2010). A natural assumption to make, and one supported unequivocally in research, is that a link exists between traumatic experiences and mental health service use (Elhai, North, \& Frueh, 2005; Briggs, et al., 2013)

Previous studies in the area of mental health service use have several limitations. First, the mental health service use and traumatic experiences link notwithstanding (Elhai, North, \& Frueh, 2005; Briggs, et al., 2013); more data is needed with regards to this link within the adolescent population. Second, the data that do exist are overflowing with studies exploring the link between service use and specific types of trauma, particularly childhood sexual and physical abuse (Tang, et al., 2006; Chartier, et al., 2007; Bonomi, et al., 2008). Research is needed to explore patterns of service use and all types of interpersonal and noninterpersonal trauma profiles. Third, there is a lack of trauma research where a person-centered approach is taken, particularly within this age group (Shevlin \& Elklit, 2008; Ford, Elhai, Connor, \& Frueh, 2010), using analytical methods such as latent class analysis to identify those who share similar trauma profiles and to then investigate patterns of service use amongst these adolescent subgroups. And fourth, a limited number of studies explore parent-adolescent agreement (concordance) on reports of service use (Williams, Lindsey, \& Joe, 2011; Waters, Stewart-Brown, \& Fitzpatrick, 2003). Parent and adolescent concordance in 
this area plays a pivotal role in forming a family's service use continuum (Williams, Lindsey, \& Joe, 2011). Discordance on matters such as reporting the extent of an adolescents emotional and behavioural problems, identifying treatment areas (Yeh \& Weisz, 2001), and treatment receptiveness (Bussing, et al., 2010) can eventually lead to an increased risk of poorer treatment outcomes (Ferdinand, van der Ende, \& Verhulst, 2006) .

In addressing previous limitations the goals of this study were to 1) identify adolescent subgroups who share similar trauma experiences; 2) explore concordance between adolescent self-report and parent reports on service use; 3) examine service use patterns amongst these adolescent subgroups; and 4) identify sociodemographic correlates of service use, trauma groups, and mental health disorders.

\section{Method}

\section{Sample}

The National Comorbidity Survey Adolescent Supplement (NCS-A) (Merikangas, et al., 2009), is a nationally representative epidemiological survery carried out in the US (2001-2004). The NCS-A was designed to study the prevalence and correlates of DSM-IV disorders (APA, 2000), and surveyed over ten thousand adolescents aged between 13 and 18. A household sub-sample ( $N=904$ adolescents) from the National Comoribidity Survey Replication (Kessler \& Merikangas, 2004) and a school sub-sample (N = 9244 adolescents) were included in the NCS-A. Additional information on adolescent development, mental and physical health, service use, and other sociodemographic variables was also collected from a parent/parent surrogate through self-administered questionnaires (SAQ). Full details of the NCS-A are available elsewhere (Kessler, et al., 2009a., 2009b). This study focuses on a sub-sample of 6483, for which information is available from both adolescent and their parent/parent surrogate. The mean age of adolescents in this sub-sample was $15.08(\mathrm{SD}=1.46)$, with $51.4 \%$ female $(\mathrm{N}=3333)$, and $48.6 \%$ male $(\mathrm{N}=3150)$.

\section{Measures}


Adolescent self-report service use was assessed for this study using data from the Services section of the World Health Organisation Composite International Diagnostic Interview (WHO CIDI 3.0) (Kessler \& Ustun, 2004), used within the NCS-A (Merikangas, et al., 2009). Respondents were asked if they had ever received treatment for emotional or behavioural problems, and if so what the form and setting of the treatment. Consistent with previous research (Merkangas, et al., 2011; Wang, et al., 2005), service use was classified in the following way, with any mention of the service type used: 1) mental health specialty services (MHS): a mental health professional, a mental health clinic, drug or alcohol clinic, and hospitalisation; 2) general medical services (GMS): seen by family doctor, or emergency department attendance; 3) human services (HS): using a telephone hotline, a counsellor, or a spiritual advisor; 4) complementary and alternative medicine (CAM): attendance at a self-help group, or any other kind of healer; 5) juvenile justice (JJ): mental health services provided by a probation officer, or other juvenile correction officer; 6) school services $(\mathrm{ScS})$ : attendance in a special classroom for emotional or behavioural problems, or use of a school counselling service. This study also examined whether the adolescents had ever been prescribed medication; 7) medication (MED): ever received a prescription for medication for emotional or behavioural problems. The parents also reported information on the above categories by answering the services section of the SAQ.

Trauma exposure was assessed using the PTSD section of the WHO CIDI, within the NCS-A (Merikangas, et al., 2009). Eighteen traumas were used in the latent class analysis, including those who reported having an "undisclosed trauma". Even though the true nature of this trauma is unknown, it was felt this category was important to the analysis. The adolescent has chosen not to disclose this trauma, suggesting that it elicits emotional pain, shame, or even deviance. All of which have been linked to various psychological sequelae (Nooner, et al., 2012). The 18 trauma categories represented a comprehensive list of trauma experiences consistent with those listed as criteria for PTSD in the DSM-IV; including sexual and physical assault, life-threatening accidents, serious illness, and witnessing serious injury (APA, 2000). The adolescents were then asked which of the traumas they had experienced caused them the most problems (e.g. feeling depressed, upsetting memories, trouble sleeping, concentration problems). 
The NCS-A gathered information on fifteen DSM-IV disorders, with evidence available showing a good concordance between the WHO CIDI and clinical diagnoses of the disorders (Kessler., et al., 2009c). In this study lifetime diagnoses of two substance use disorders (alcohol abuse, drug abuse), two mood disorders (dysthymia, major depressive episode) and two anxiety disorders (PTSD, generalized anxiety disorder (GAD)) were used. Sociodemographic variables included gender, race, and living arrangements (living with both biological parents, one biological parent, or neither biological parent).

\section{Analyses}

Analyses were conducted in a number of stages. First, a latent class analysis (LCA) was employed to determine if there were meaningful groups of adolescents sharing similar patterns of trauma experience in the full NCS-A sample ( $\mathrm{N}=10$ 123). The fit of five models (two-class through to six-class) was assessed using the Akaike Information Criterion (AIC) (Akaike, 1987), the Bayesian Information Criterion (BIC) (Scwartz, 1978), the sample size-adjusted Bayesian Information Criterion (ssaBIC) (Sclove, 1987), and the Lo-Mendell-Rubin adjusted likelihood ratio test (LRT) (Lo, Mendell, \& Rubin, 2001). Entropy measures determined how accurately participants were classified, with higher values (ranging from 0 to 1 ) indicating better classification (Celeux \& Soromenho, 1996). A four-class model was deemed best fit, with full details of the latent class analysis available on request. Participants were then assigned membership to one of the four classes based on posterior probabilities, with only those in an adolescent/parent pair used in further analysis in this study ( $\mathrm{N}=6483)$. A Cohen's kappa test was carried out to test the levels of agreement between adolescent and parent responses with regards to service use. Associations between the emergent trauma classes, service use, sociodemographic and clinical variables were assessed. In order to account for the complex survey sampling of the data, all analysis included sampling weights. Analyses were carried out using Mplus (v7) (Muthen \& Muthen, 2012).

\section{Results}

\section{Adolescent Trauma Patterns}

LCA tested five models (two-class through to six-class) for best fit. The LRT becomes non-significant with the five-class solution ( $p=.76$ ), suggesting that the four-class model should be accepted. Further support 
for accepting this model comes from lower AIC, BIC and ssaBIC values for the four-class solution, and an acceptable entropy value of 0.76 . Based on these results, the profile plot of class membership for a four class solution of the participants used in this study $(\mathrm{N}=6483)$ is displayed in Figure 1.

Class 1 ('high risk'), was characterized by adolescents displaying relatively high probabilities of having endorsed each of the 18 traumas (with the exception of being exposed to poison, living in a place of terror, and being beaten by a romantic partner). Class 2 ('sexual assault'), was characterized by adolescents displaying comparatively higher probabilities of experiencing sexual assault and rape. Class 3 ('non-sexual risk'), was characterized by adolescents displaying relatively higher probabilities of endorsing witnessing injury or death, experiencing a major disaster, having an accident other than in a car, and being beaten by someone other than a parent or partner. Class 4 ('low risk'), was characterized by adolescents displaying consistently low probabilities of endorsing any of the traumas (with the exception of death of a loved one, which had high endorsement across all classes) and this class was considered the baseline.

\section{Adolescent and Parental Agreement on Service Use}

Moderate (Landis \& Koch, 1977) levels of agreement were found between adolescent/parent responses for mental health specialty services $(K=.61, p<.001)$, and medication use $(K=.69, p<.001)$. Levels of agreement were below the acceptable range for the remaining services; general medical services $(K=.29$, $p$ $<.001)$, human services $(\mathrm{K}=.25, \mathrm{p}<.001)$, complementary and alternative medicine $(\mathrm{K}=.18, \mathrm{p}<.001)$, juvenile justice $(\mathrm{K}=.35, \mathrm{p}<.001)$, and school services $(\mathrm{K}=.38, \mathrm{p}<.001)$. Figure 2 shows the variation in service use for parent/adolescent responses.

\section{Adolescent Service Use Patterns and Trauma Class}

The services utilised by this group of adolescents varies across the trauma classes. Almost eighty percent of those in the 'high risk' class $(73.3 \%, N=44)$ accessed mental health specialty services, with over half of this group having used school services $(53.3 \%, N=32)$. Medication, complementary alternative medicine, and human services were found to have usage frequencies of over $30 \%$ for this group $(35 \%, N=21 ; 33.3 \%$, $N=20$; and $31.7 \%, N=19$ respectively). Lower frequencies in this 'high risk' class were found for general medical services $(16.7 \%, N=10)$, and services within the juvenile justice system $(16.7 \%, N=10)$. 
Similar to the 'high risk' class, a high proportion of those in the 'sexual assault risk' class $(55.3 \%, N=146)$ used mental health specialty services, with the lowest frequencies within this class found for general medical services $(10.2 \%, N=27)$, and services within juvenile justice $(6.4 \%, N=17)$. Lower frequency rates were found across all service types within the 'non-sexual risk' class. The highest proportion within this class utilised mental health specialty services $(36.8 \%, N=329)$, with fewer than $30 \%$ making use of school services $(27.3 \%, N=244)$. Lowest usage frequencies in this class were found for general medical services $(6 \%, N=54)$ and juvenile justice mental health services $(5.8 \%, N=52)$. As the 'low risk' class by its nature consists of adolescents with very limited experience of trauma, and as only a small proportion of those in the 'low risk' class have used any kind of mental health service (17.4\% accessed mental health specialty services, with only $3.7 \%$ accessing general medical services), this class was not included in further analyses.

The mean age of first service use across the three trauma classes ranged from 10.66 ( $\mathrm{SD}=3.74$; 'high risk' class first use of mental health specialty services) to 15.56 years ( $\mathrm{SD}=1.33$; 'high risk' class first use of juvenile justice services). The mean age of the trauma each group highlighted as being the traumatic event that caused the most problems was also calculated. For the 'high risk' class the most problematic trauma was being beaten by their caregivers, with a mean age of 5.24 (SD 4.85) for first experiences of this event. The earliest mean age for first service use in the 'high risk' class is 10.66 (SD 3.74) for mental health specialty services. As would be expected the 'sexual assault risk' class endorsed rape and sexual assault as the traumas that caused most problems, with a first experience mean age of 10.46 (SD 4.64) and 9.38 (SD 5.00) respectively. The youngest mean age for first service use in this class is again for mental health specialty services (11.65, SD 3.26). The 'non-sexual risk' class endorsed the death of a loved one as the most problematic trauma, with a mean age of first experience of 11.28 (SD 4.16). This age is again just below the mean age for first use of mental health specialty services for this class (11.54 SD=3.12).

\section{Associations Between Adolescent Service Use and Trauma Class}

A multinomial logistic regression was then carried out to assess any associations between trauma class membership and gender, race, and living arrangements (living with both biological parents, one biological parent, or neither biological parent). The results are shown in Table 1. Those in the 'sexual assault risk' 
class were over seven times as likely to be female $(\mathrm{OR}=7.65, \mathrm{p}<.001)$ and over 11 times as likely to live with neither biological parent $(\mathrm{OR}=11.35, \mathrm{p}<.001)$; a characteristic that was significant in all trauma classes. Race did not appear to be indicative of any class membership, with the exception of those in the 'non-sexual risk' class who were almost twice as likely to be Hispanic $(\mathrm{OR}=1.71, \mathrm{p}<.01)$.

Binary logistic regression was then used to predict service use within the three trauma classes. The results are shown in Table 2. Most mental health service types were significantly associated with the trauma classes, with the exception of human services and the 'high risk' class and general medical services and the 'non-sexual risk' class. That said, variations were found as to which service type had the higher probability of adolescent use across the trauma classes. Those in the 'high risk' class were over twenty times more likely to have received mental health treatment within school services $(\mathrm{OR}=20.75, \mathrm{p}<0.001)$. Whereas, adolescents in the 'sexual assault risk' class were just under four times more likely to use school services $(\mathrm{OR}=3.75, \mathrm{p}<0.001)$, but were almost eleven times more likely to have received mental health services within the juvenile justice system $(\mathrm{OR}=10.97, \mathrm{p}<0.001)$. Receiving mental health services within juvenile justice was also found to have the highest probability within the 'non-sexual risk' class, with adolescents in this group being over six times more likely to have used this service than not $(\mathrm{OR}=6.20, \mathrm{p}<0.001)$. Those services that had the lowest probability of use also differed across the trauma classes. In contrast to the highest probabilities, the lowest likelihood of service use within the 'high risk', and 'non-sexual risk' classes were found to be for the same service category; medication $(\mathrm{OR}=5.28, \mathrm{p}<0.001$; $\mathrm{OR}=1.75$, $\mathrm{p}<0.01$, respectively). The 'sexual assault risk' class had the lowest probability of making use of general medical services, with adolescents in this group being just over two and a half times more likely to have utilised this service $(\mathrm{OR}=2.56, \mathrm{p}<0.01)$.

\section{Trauma Classes, Clinical Disorders and Adolescent Service Use}

Prevalence rates of the six clinical disorders within this group of adolescents varied across gender. It was found that males $(N=3150)$ displayed higher rates of both substance use disorders; alcohol abuse $(7 \%)$, drug abuse $(9 \%)$, compared to females $(\mathrm{N}=3333 ; 5 \%$, and $6.5 \%$ respectively). Females were found to have higher prevalence rates of the mood and anxiety disorders; dysthymia (4.5\%), major depressive 
episode (17.1\%), GAD (4.3\%), and PTSD (5.5\%), compared to males $(2.1 \% ; 8.8 \% ; 1.6 \% ; 1.5 \%$;

respectively).

Table 3 displays the results from the logistic regression analysis used to explore any association between the clinical disorders and the trauma classes. It was found that all substance use, mood, and anxiety disorders were significantly associated with the trauma classes, with those in the 'high risk' class displaying the highest odds for experiencing all, when compared to the baseline group. High odds ratios were also found for substance use disorders within the remaining trauma classes, with those in the 'sexual assault risk' class over eight times as likely to have a diagnosis of drug abuse $(\mathrm{OR}=8.25, \mathrm{p}<.001)$, and those in the 'non-sexual risk' class almost five times as likely to have an alcohol abuse diagnosis $(\mathrm{OR}=4.76, \mathrm{p}<$. 001).

The final step in the analysis was to investigate the association between these clinical disorders and the type of services used by the adolescents. The results are shown in Table 4. Those who met the clinical diagnoses for alcohol and drug abuse were over five times $(\mathrm{OR}=5.35, \mathrm{p}<.001)$ and seven times $(\mathrm{OR}=$ $7.40, \mathrm{p}<.001$ ) as likely to have used services provided by the juvenile justice system. With the exception of major depressive episode, the remaining clinical disorders (dysthymia, GAD, and PTSD) displayed the highest probabilities for using mental health specialty services compared to other available services.

\section{Discussion}

The aim of this study was to explore trauma profiles and service use patterns within a large sample of adolescents from the USA, and to then investigate these in terms of clinical outcomes. The clustering of trauma experiences within this population of 6483 adolescents was assessed, with four trauma 'sub-groups' identified. These were labelled as 'high risk', 'sexual assault risk', 'non-sexual risk', and 'low risk'. Just over $80 \%$ of the adolescents were to be found in the 'non-sexual risk' and 'low risk' classes. The 'low risk' class represented those adolescents who had very low probabilities of experiencing any of the traumas, with 
the exception of the death of a loved one. A trauma experience common to all classes. The 'non-sexual risk' class represented those adolescents at increased risk of traumas of a non-sexual, and non-interpersonal nature. As the name suggests the 'sexual assault risk' class were those who experienced sexual traumas at levels similar to those in the 'high risk' class. The smallest proportion of this adolescent population (.9\%) was to be found in the 'high risk' class, where relatively high probabilities of experiencing most traumas were displayed. The emergence of these four classes is consistent with previous trauma research (Shevlin \& Elklit, 2008; Houston, et al., 2011)

One of the unique aspects of the NCS-A is that a parent/parent surrogate is also surveyed about the adolescent. Only those adolescents with matching responses from a parent were used in this study, with adolescent/parent concordance investigated in terms of service use. Apart from items relating to mental health specialty services and medication use, overall adolescent/parent concordance was below the 0.6 levels deemed moderate (Landis \& Koch, 1977). These findings are reflected in previous work, where levels of agreement between parents and adolescents on service use have been described as "acceptable" (Merikangas, et al., 2011, p. 34), where results are limited to any mental health treatment or any service type. Previous work, looking at parent/service record concordance, supports the substantial levels of agreement found in this study for medication use and also the weak levels for school services (Hoagwood, et al., 2000). The wide variation on adolescent/parent concordance in this study has possibly arisen for a number of reasons. First, the level of visibility of the service may play a part on reporting its use. For example, mental health services provided in schools may be relatively invisible to those receiving them, due to terminology that may be used to avoid any stigma surrounding the use of such resources, resulting in under reporting by adolescents in usage rates. Second, higher levels of concordance may be present where parents may have to play an active role, such as helping to administer prescribed medication. And third, adolescents may wish to keep their attendance at particular services from their parents, for example if it is to help with the negative sequelae of sexual trauma. Notwithstanding the relatively low concordance rates between adolescents and parents in some instances is a weakness and could be viewed as a limitation of the study. 
Whilst there were variations in the levels of adolescent/parent concordance, the overall service use patterns described by both groups were similar, and consistent with previous research (Burns, et al., 1995). This pattern was also then reflected when exploring service use frequencies within the trauma classes. The "high risk', 'sexual risk', and 'non-sexual risk' classes all displayed higher percentages of using mental health specialty services, school services, and medication, with a slight increase in the use of human services. Does this suggest that there are resources such as those provided by general medical services and complementary and alternative medicine (CAM) that are not being utilised by those who need them or that they are thought to be not effective in the treatment of emotional and behavioural problems? Research suggests that in the US in 2007 estimated usage rates of CAM therapies by the under 18's for anxiety/stress related conditions was just $4.8 \%$, with higher usage rates amongst females and those who live in a family with two parents (Barnes, et al., 2008). Research into the effectiveness of CAM therapies is still somewhat poor (van der Watt, Laugharne, \& Janca, 2008), but some do suggest that it can improve symptoms of anxiety but only when considered along with more traditional healthcare providers (Bystritsky, et al., 2012).

The higher percentages of those adolescents receiving medication to treat emotional or behavioural problems seen in this study reflect the growing concern in recent literature. Research, particularly in the United States, has identified an alarming rise in the number of individuals prescribed such medications, with a 22\% rise between 2001 and 2010 (Smith, 2012). Whilst medication is a valuable tool to mental health professionals, inappropriate prescribing can be detrimental, and may contribute to the higher usage rates as witnessed here. That said, whilst higher frequencies of medication were evident in this study it was found to have the lowest likelihood of use within the 'high risk' and 'non-sexual risk' trauma classes, and only showed a small association with one clinical disorder. Those with dysthymia were almost twice as likely $(\mathrm{OR}=1.82, \mathrm{p}<.05)$ to have been prescribed medication for emotional or behavioural problems, compared to those without.

Results showed that those in the 'sexual assault risk' class were more likely to be female and almost ten times as likely ( $\mathrm{OR}=9.71, \mathrm{p}<.001)$ to have used human services (such as counselling); with human services showing strong associations with mood and anxiety disorders. This is consistent with previous 
research in that sexual abuse is more likely to occur amongst adolescent females (Davis, Matthews, \& Twamley, 1999) and can lead to later mental health problems such as anxiety and depression (Spataro, et al, 2004), which are both disorders with higher female prevalence rates (Freeman \& Freeman, 2013). The provision of effective treatments for adolescents with depression or anxiety is greatly limited by the organisation of services for this age group, a failure to effectively diagnose disorders and by public stigma (National Collaborating Centre for Mental Health, 2005). However, effective treatments that come under the human services category are available (Watanabe, et al, 2007). For example, Coginitive Behaviour Therapy (CBT) has been recommended for mild to moderate depression (National Collaborating Centre for Mental Health, 2005), and has been shown to be effective in adolescent anxiety (James, et al, 2013).

This study found higher prevalence rates for alcohol and drug abuse amongst the males, consistent with previous research where they have been found more likely to suffer from a substance use disorder (Freeman \& Freeman, 2013). Males were also found here to be more likely to be in the 'non-sexual risk' trauma class, with this class almost five times as likely to have used services provided by schools $(\mathrm{OR}=$ $4.79, \mathrm{p}<.001)$ and over six times as likely within the juvenile justice system $(\mathrm{OR}=6.20, \mathrm{p}<.001)$. Significant associations were then found between juvenile justice services and alcohol abuse $(\mathrm{OR}=5.35, \mathrm{p}$ $<.001)$ and drug abuse $(\mathrm{OR}=7.40, \mathrm{p}<.001)$. Substance use disorders amongst adolescents have been shown to have far-reaching consequences, particularly in relation to delinquency and criminal behaviour (Winters, 1999). Strong links have been shown to exist between adolescent substance abuse and conduct disorder (Crowley \& Riggs, 1995), with the juvenile justice system mandating treatment as a result of the abuse and subsequent conduct (Jainchill, 1997). And, as has been shown here, males consistently show a stronger association between substance use and juvenile crimes (National Institute of Justice, 2000).

One of the main limitations to this study is that service use is only examined in terms of whether or not the adolescent has, at any time in their life, used such resources. In order to gain a fuller picture of service use patterns further research should examine; the success rate of resources used, completion of therapies, and premature treatment cessation. Furthermore, the definition and classification of service usage applied in this and previous research adds some limitations insofar as identifying specific and additional services used within each of the broader categories concerned. Whilst the use of this classification method was 
appropriate here further study of the service types used within each of the categories would help address such limitations.

This study has shown that adolescents belong to trauma sub-groups based on the nature of their trauma experiences. Associations to a range of mood and anxiety disorders were then shown to exist, with patterns of service use showing higher rates of use for mental health specialty services, school services and prescription of medication. The evidence provided here raises some issues for future research and for providers of adolescent mental health services. For example, further research is needed into the differences between adolescent and adult service requirements, with service providers urged to be mindful of such differences. The developmental age of the adolescent, along with factors such as their gender and cultural background should also be considered when offering mental health services. Consistent with the literature, this study has shown that only a small proportion of those who may be in need are utilising mental health services. However, this study may go some way to understanding the trauma backgrounds, demographic predictors and clinical disorders that lead some adolescents to mental health services.

\section{References}

Akaike, H. (1987). Factor-analysis and Aic. Psychometrika , 52, 317-332.

APA. (2000). Diagnostic and Statistical Manual of Mental Health Disorders DSM-IV-TR. (4th, Ed.) Washington, DC: American Psychiatric Association.

Barnes, P. M., Bloom, B., Division of Health Interview Statistics, National Center for Health Statistics, Nahin, R. L., National Center for CAM, et al. (2008). Complementary and Alternative Medicine Use 
Among Adults and Children: United States, 2007. Centers for Disease Control and Prevention. National Center for Health Statistics.

Bond, G. R., Drake, R. E., Mueser, K. T., \& Latimer, E. (2001). Assertive Community Treatment for People with Severe Mental Illness. Dis Manage Health Outcomes , 9 (3), 141-159.

Bonomi, A. E., Anderson, M. L., Rivara, F. P., Cannon, E. A., Fishman, P. A., Carrell, D., et al. (2008). Health Care Utilization and Costs Associated with Childhood Abuse. J Gen Intern Med , 23 (3), 294-299.

Briggs, E. C., Fairbank, J. A., Greeson, J. K., Layne, C. M., Steingberg, A. M., Amaya-Jackson, L. M., et al. (2013). Link Between Child and Adolescent Trauma Exposure and Service Use Histories in a National Clinic-Referred Sample. Psychological Trauma: Theory, Research, Practice, and Policy, 5 (2), 101-109.

Burns, B. J., Costello, E. J., Angold, A., Tweed, D., Stangl, D., Farmer, E. M., et al. (1995). Children's mental health service use across service sectors. Health Affairs , 14 (3), 147-159.

Bussing, R., Zima, B.T., Mason, D.M., Porter, P.C. \& Garvan, C.W. (2011). Receiving Treatment for Attention-Deficit Hyperactivity Disorder: Do the Perspectives of Adolescents Matter? Journal of Adolescent Health, 49(1): 7-14.

Bystritsky, A., Hovav, S., Sherbourne, C., Stein, M. B., Rose, R. D., Campbell-Sills, L., et al. (2012). Use of Complementary and Alternative Medicine in a Large Sample of Anxiety Patients. Psychosomatics , 53, 266-272.

Carr, S., \& Francis, A. (2009). Childhood maltreatment and adult personality disorder symptoms in a nonclinical sample. Australian Psychologist , 44(3):146-155.

Celeux, G., \& Soromenho, G. (1996). An entropy criterion for assessing the number of clusters in a mixture model. Journal Classif, 13, 195-212.

Chartier, M. J., Walker, J. R., \& Naimark, B. (2007). Childhood Abuse, Adult Health, and Health Care Utilization: Results from a Representative Community Sample. Am J Epidemiol , 165 (9), 1031-1038.

Crowley, T. J., \& Riggs, P. D. (1995). Adolescent Substance Use Disorder with Conduct Disorder and Comorbid Conditions. In E. Rahdert, \& D. Czechowicz (Eds.), Adolescent Drug Abuse: Clinical Assessment and Therapeutic Interventions (pp. 49-111). Rockville, MD: Research Monograph Series 156, National Institute on Drug Abuse (NIDA).

Davis, M. C., Matthews, K. A., \& Twamley, E. W. (1999). Is life more difficult on Mars or Venus? A metaanalytic review of sex differences in major and minor life events. Annals of Behavior , 21 (1), 83-97.

de Almeida, J. M., \& Killaspy, H. (2011). Long-term Mental Health Care for People with Severe Mental Disorders. EU: Impact Consortium Report.

Elhai, J. D., North, T. C., \& Frueh, B. C. (2005). Health Service Use Predictors Among Trauma Survivors: A Critical Review. Psychological Services , 2 (1), 3-19.

Fairbank, J. A. (2008). The epidemiology of trauma and trauma related disorders in children and youth. PTSD Research Quarterly, 19 (1), 1-7.

Ferdinand, R.F., van der Ende, J. \& Verhulst, F.C. (2006). Prognostic value of parent-adolescent disagreement in a referred sample. Eur Child Adolesc Psyciatry 15:156-162. 
Finkelhor, D., Ormrod, R. K., \& Turner, H. A. (2007). Poly-victimization: A neglected component in child victimization. Child Abuse \& Neglect, 31, 7-26.

Ford, J.D. \& Blaustein, M.E. (2013) Systematic Self-Regulation: A Framework for Trauma-Informed Services in Residential Juvenile Justice Programs. J Fam Viol, 28, 665-677.

Ford, J.D., Elhai, J.D., Connor, D.F. \& Frueh, B.C. (2010). Poly-victimization and Risk of Posttraumatic, Depressive, and Substance Use Disorders and Involvement in a National Sample of Adolescents. $J$ Adolescent Health, 46, 545-552.

Fraynt, R., Ross, L., Baker, B.L., Rysatd, I., Lee, J. \& Briggs, E.C. (2014). Predictors of Treatment Engagement in Ethnically Diverse, Urban Children Receiving Treatment for Trauma Exposure. $J$ Traumatic Stress , 27, 66 - 73.

Freeman, D., \& Freeman, J. (2013). The Stressed Sex: Uncovering the truth about men, women, and mental health. Oxford: Oxford University Press.

Gearing, R. E., Schwalbe, C. S., \& Short, K. D. (2012). Adolescent adherence to psychosocial treatment: Mental health clinicians' perspectives on barriers and promoters. Psychotherapy Research, 22(3): 317-326.

Gibb, B. E., Chelminski, I., \& Zimmerman, M. (2007). Childhood emotional, physical and sexual abuse, and diagnoses of depressive and anxiety disorders in adult psychiatric outpatients. Depression and Anxiety, 24(4):256-263.

Gopalan, G., Goldstein, L., Klingenstein, K., Sicher, C., Blake, C., \& McKay, M. M. (2010). Engaging Families into Child Mental Health Treatment: Updates and Special Considerations. J Can Acad Child Adolesc Psychiatry, 19 (3), 182-196.

Green, J. G., McLaughlin, K. A., Berglund, P. A., Gruber, M. J., Sampson, N. A., Zaslavsky, A. M., et al. (2010). Childhood adversities and adult psychopathology in the National Comorbidity Survey Replication (NCS-R) I: Associations with first onset of DSM-IV Disorders. Arch Gen Psychiatry, 67(2):113-133.

Grisso, T. (2008). Adolescent Offenders with Mental Disorders. The Future of Children , 18 (2), 143-164.

Guadiano, B. A., \& Zimmerman, M. (2010). The relationship between childhood trauma history and the psychotic subtype of major depression. Acta Psychiatrica Scandinavica , 121(6):462-470.

Hoagwood, K., \& Erwin, H. D. (1997). Effectiveness of School-Based Mental Health Services for Children: A 10-year Research Review. Journal of Child and Family Studies , 6 (4), 435-451.

Hoagwood, K., Horwitz, S., Stiffman, A., Weisz, J., Bean, D., Rae, D., et al. (2000). Concordance between parent reports of children's mental health services and service records: The Services Assessment for Children and Adolescents (SACA). Journal of Child and Family Studies , 9 (3), 315-331.

Houston, J. E., Shevlin, M., Adamson, G., \& Murphy, J. (2011). A person-centred approach to modelling population experiences of trauma and mental illness. Soc Psychiatry Psychiatr Epidemiol , 46, 149-157.

Jagdeo, A., Cox, B. J., Stein, M. B., \& Sareen, J. (2009). Negative Attitudes Toward Help Seeking for Mental Illness in 2 Population-Based Surveys From the United States and Canada. Can J Psychiatry, 54 (11), 757-766. 
Jainchill, N. (1997). Therapeutic Communities for Adolescents: The same and not the same. In G. De Leon (Ed.), Community as Method: Therapuetic Communites for Special Populations and Special Settings (pp. 161-177). Westport, CT: Praeger.

James, A. C., James, G., Cowdery, F. A., Soler, A., \& Choke, A. (2013). Cognitive Behavioral Therapy for anxiety disorders in children and adolescents. Cochrane Database of Sytematic Reviews , 6.

Jorm, A. F. (2012). Mental Health Literacy: Empowering the Community to Take Action for Better Mental Health. American Psychologist , 67 (3), 231-243.

Kessler, R. C., \& Merikangas, K. R. (2004). The National Comorbidity Survey Replication (NCS-R): background and aims. Int J Meth Psych Res , 13, 60-68.

Kessler, R. C., \& Ustun, T. B. (2004). The World Mental Health (WMH) Survey Initiative version of the World Health Organisation (WHO) Composite International Diagnostic Interview (CIDI). Int J Meth Psych Res , 13 (2), 93-121.

Kessler, R. C., Avenevoli, E., Costello, E. J., Green, J. G., Gruber, M. J., Heeringa, S., et al. (2009a). Design and field procedures in the US National Comorbidity Survey Replication Adolescent Supplement (NCS-A). Int J Meth Psych Res , 18 (2), 69-83.

Kessler, R. C., Avenevoli, S., Costello, E. J., Green, J. G., Gruber, M. J., Heeringa, S., et al. (2009b). National Comorbidity Survey Replication Adolescent Supplement (NCS-A): II. Overview and Design. $J$ Am Acad Child \& Adol Psych , 48 (4), 380-385.

Kessler, R. C., Avenevoli, S., Green, J., Gruber, M. J., Guyer, M., He, Y., et al. (2009c). National Comorbidity Survey Replication Adolescent Supplement (NCS-A): III. Concordance of DSM-IV/CIDI Diagnoses with Clinical Reassessments. J Am Acad Child \& Adol Psych , 48 (4), 386-399.

Killaspy, H. (2007). From the asylum to community care: learning from experience. British Medical Bulletin, 1-14.

Landis, J. R., \& Koch, G. G. (1977). The measurement of observer agreement for categorical data. Biometrics , 33, 159-174.

Lo, Y., Mendell, N. R., \& Rubin, D. B. (2001). Testing the number of components in a normal mixture. Biometrika , 88 (3), 767-778.

Mackenzie, C. S., Erickson, J., Deane, F. P., \& Wright, M. (2013). Changes in Attitudes toward Seeking Mental Health Services: A 40-Year Cross-Temporal Meta-Analysis. Clinical Psychology Review .

Marcus, S. C., \& Olfson, M. (2010). National Trends in the Treatment for Depression From 1998 to 2007. Arch Gen Psychiatry, 67 (12), 1265-1273.

Merikangas, K. R., Avenevoli, S., Costello, E. J., Koretz, D., \& Kessler, R. C. (2009). The National Comorbidity Survey Adolescent Supplement (NCS-A): I. Background and Measures. $J$ Am Acad Child Adolesc Psychiatry, 48 (4), 367-369.

Merikangas, K. R., He, J.-P., Brody, D., Fisher, P. W., Bourdon, K., \& Koretz, D. S. (2010). Prevalence and Treatment of Mental Disorders Among US Children in the 2001-2004 NHANES. Pediatrics , 125, 75-81. 
Merikangas, K. R., He, J.-P., Burstein, M., Swanson, S. A., Avenevoli, S., Cui, L., et al. (2010). Lifetime Prevalence of Mental Disorders in US Adolescents: Results from the National Comorbidity Survey Adolescent Supplement (NCS-A). J Am Acad Child Adolesc Psychiatry, 49 (10), 980-989.

Merikangas, K. R., He, J.-P., Burstein, M., Swendsen, J., Avenevoli, S., Case, B., et al. (2011). Service Utilization for Lifetime Mental Disorders in U.S Adolescents: Results of the National Comorbidity Survey - Adolescent Supplement (NCS-A). J Am Acad Child Adolesc Psychiatry, 50 (1), 32-45.

Mullen, P. E., Walton, V. A., Romans-Clarkson, S. E., \& Herbison, P. (1988). Impact of Sexual and Physical Abuse on Women's Mental Health. The Lancet, 331(8590):841-845.

Muthen, L. K., \& Muthen, B. O. (2012). Mplus User's Guide (7th ed.). Los Angeles, California.

National Collaborating Centre for Mental Health. (2005). Depression in Children and Young People:

Identification and management in primary, community and secondary care. National Institute for Clinical Excellence. British Psychological Society.

National Institute of Justice. (2000). 1999 Annual Report on Drug Use Among Adult and Juvenile Arrestees. Washington, DC: National Insitute of Justice.

Nooner, K. B., Linares, L. O., Batinjane, J., Kramer, R. A., Silva, R., \& Cloitre, M. (2012). Factors Related to Posttraumatic Stress Disorder in Adolescence. Trauma Violence Abuse , 13 (3), 153-166.

Olfson, M., Marcus, S. C., Druss, B., Elinson, L., Tanielian, T., \& Pincus, H. A. (2002). National Trends in the Outpatient Treatment of Depression. JAMA , 287 (2), 203-209.

Roberts, E., Cumming, J., \& Nelson, K. (2005). A Review of Economic Evaluations of Community Mental Health Care. Medical Care Research and Review , 62 (5), 503-543.

Sclove, S. L. (1987). Application of model-selection criteria to some problems in multivariate-analysis. Psychometrika , 52, 333-343.

Scwartz, G. (1978). Estimating the dimension of a model. Ann Stat , 6, 461-464.

Shevlin, M., \& Elklit, A. (2008). A latent class analysis of adolescent adverse life events based on a Danish national youth probability sample. Nord J Psychiatry, 62, 218-224.

Skre, I., Friborg, O., Breivik, C., Johnsen, L. I., Arnesen, Y., \& Wang, C. E. (2013). A school intervention for mental health literacy in adolescents: effects of a non-randomized cluster controlled trial. BMC Public Health , 13, 873-887.

Smith, B. L. (2012). Inappropriate Prescribing. Monitor on Psychology, 43 (6), 36-40.

Spataro, J., Mulle, P. E., Burgess, P. M., Wells, D. L., \& Moss, S. A. (2004). Impact of child sexual abuse on mental health. British Journal of Psychiatry, 184, 416-421.

Tang, B., Jamieson, E., Boyle, M., Libby, A., Gafni, A., \& MacMillan, H. (2006). The influence of child abuse on the pattern of expenditures in women's adult health service utilization in Ontario, Canada. Social Science \& Medicine , 63, 1171-1719.

Thornicroft, G., \& Tansella, M. (2003). What are the arguments for community-based mental health care? Health Evidence Network Report. Copenhagen: WHO Regional Office for Europe. 
US Department of Health and Human Services. (1999). Chapter 2: The Fundamentals of Mental Health and Mental Illness. In Mental Health: A Report of the Surgeon General (pp. 27-116). MD, USA: Department of Health and Human Services, Substance Abuse and Mental Health Services Administration, Center for Mental Health Services.

van der Watt, G., Laugharne, J., \& Janca, A. (2008). Complementary and alternative medicine in the treatment of anxiety and dperession. Current Opinion in Psychiatry, 21 (1), 37-42.

Wang, P. S., Lane, M., Olfson, M., Pincus, H. A., Wells, K. B., \& Kessler, R. C. (2005). Twelve-Month Use of Mental Health Services in the United States. Arch Gen Psychiatry, 62 (629-640).

Watanabe, N., Hunot, V., Omori, I. M., Churchill, R., \& Furukawa, T. A. (2007). Psychotherapy for depression among children and adolescents: a systematic review. Acta Psychiatr Scand, 116, 84-95.

Waters, E., Stewart-Brown, S., \& Fitzpatrick, R. (2003). Agreement between adolescent self-report and parent reports of health and well-being: results of an epidemiological study. Child:Care, Health \& Development, 29 (6), 501-509.

Weisz, J. R., \& Kazdin, A. E. (Eds.). (2010). Evidence-Based psychotherapies for children and adolescents (2nd ed.). New York, NY: Guilford Press.

Williams, C. D., Lindsey, M., \& Joe, S. (2011). Parent-adolescent concordance on perceived need for mental health services and its impact on service use. Children and Youth Services Review, 33, 2253-2260.

Winters, K. C. (1999). Treatment of Adolescents with Substance Use Disorders. Substance Abuse and Mental Services Admin. USA: (SAMHSA).

Yeh, M. \& Weisz, J.R. (2001). Why Are We Here at the Clinic? Parent-Child (Dis)Agreement on Referral Problems at Outpatient Treatment Entry. Journal of Consulting and Clinical Psychology 69(6): 1018-1025.

Figure Profile Plot of Adolescent Trauma based on Latent Class Membership ( $\mathrm{N}=6483$ )

Figure 2 Adolescent/Parent Service Use Concordance 
Table 1

Demographic variables predicting trauma class membership ${ }^{\mathrm{A}}$

\begin{tabular}{lccc}
\hline $\begin{array}{r}\text { Trauma } \\
\text { Classes }\end{array}$ & $\begin{array}{c}\text { Class1 } \\
\text { High risk }\end{array}$ & $\begin{array}{c}\text { Class2 } \\
\text { Sexual assault } \\
\text { risk }\end{array}$ & $\begin{array}{c}\text { Class3 } \\
\text { Non-sexual } \\
\text { risk }\end{array}$ \\
\cline { 2 - 4 } Demographics & OR & OR & OR \\
\hline & & $(95 \% \mathrm{CI})$ & $(95 \% \mathrm{CI})$ \\
\hline Female $^{\text {B }}$ & $2.91^{*}$ & $7.65^{* * *}$ & $0.51^{* * *}$ \\
& $(1.21-7.00)$ & $(4.26-13.75)$ & $(0.41-0.64)$ \\
Hispanic $^{\text {C }}$ & 1.03 & 1.56 & $1.71^{* *}$ \\
& $(0.46-2.30)$ & $(0.81-3.01)$ & $(1.25-2.33)$ \\
Black $^{\text {C }}$ & 0.57 & 0.72 & 1.32 \\
Neither Parent $_{\text {D }}$ & $(0.17-1.94)$ & $(0.44-1.18)$ & $(0.99-1.76)$ \\
& $(2.07-24.97)$ & $(6.51-19.79)$ & $(2.33-4.65)$ \\
1 Parent $^{\text {D }}$ & $2.96^{*}$ & $3.36^{* * *}$ & $2.04^{* * *}$ \\
\hline
\end{tabular}

${ }^{\mathrm{A}}$ Each trauma class is compared to the low risk class

${ }^{\mathrm{B}}$ Reference: male 
${ }^{\mathrm{C}}$ Reference: white

${ }^{\mathrm{D}}$ Reference: living with both biological parents

${ }^{*} \mathrm{p}<0.05 ;{ }^{* *} \mathrm{p}<0.01,{ }^{* * *} \mathrm{p}<0.001$ 


\section{Table 2}

Trauma class membership predicting Service Use

\begin{tabular}{|c|c|c|c|c|c|c|c|}
\hline $\begin{array}{r}\text { Servic } \\
e s\end{array}$ & MHS & GMS & HS & CAM & $\mathrm{JJ}$ & $\mathrm{ScS}$ & Med \\
\hline Trauma Classes & $\begin{array}{c}\text { OR } \\
(95 \% \mathrm{CI})\end{array}$ & $\begin{array}{c}\text { OR } \\
(95 \% \mathrm{CI})\end{array}$ & $\begin{array}{c}\text { OR } \\
(95 \% \mathrm{CI})\end{array}$ & $\begin{array}{c}\text { OR } \\
(95 \% \mathrm{CI})\end{array}$ & $\begin{array}{c}\text { OR } \\
(95 \% \mathrm{CI})\end{array}$ & $\begin{array}{c}\text { OR } \\
(95 \% \mathrm{CI})\end{array}$ & $\begin{array}{c}\text { OR } \\
(95 \% \mathrm{CI})\end{array}$ \\
\hline $\begin{array}{l}\text { Class } 1 \\
\text { High Risk }\end{array}$ & $\begin{array}{c}14.48^{* * *} \\
(6.17-33.98)\end{array}$ & $\begin{array}{c}5.64^{* *} \\
(2.10-15.18)\end{array}$ & $\begin{array}{c}11.79 \\
(5.01-27.71)\end{array}$ & $\begin{array}{c}8.40^{* * *} \\
(3.58-19.71)\end{array}$ & $\begin{array}{c}15.77^{* * *} \\
(5.97-41.60)\end{array}$ & $\begin{array}{c}20.75^{* * *} \\
(9.53-45.18)\end{array}$ & $\begin{array}{c}5.28^{* * *} \\
(2.37-11.74)\end{array}$ \\
\hline $\begin{array}{l}\text { Class } 2 \\
\text { Sexual Risk }\end{array}$ & $\begin{array}{c}6.41^{* * *} \\
(4.37-9.41)\end{array}$ & $\begin{array}{c}2.56^{* *} \\
(1.34-4.87)\end{array}$ & $\begin{array}{c}9.71^{* * *} \\
(6.11-15.43)\end{array}$ & $\begin{array}{c}6.00^{* * *} \\
(3.59-10.06)\end{array}$ & $\begin{array}{c}10.97^{* * *} \\
(5.13-23.46)\end{array}$ & $\begin{array}{c}3.75^{* * *} \\
(2.49-5.66)\end{array}$ & $\begin{array}{c}4.77^{* * *} \\
(2.97-7.66)\end{array}$ \\
\hline $\begin{array}{l}\text { Class } 3 \\
\text { Non-Sexual Risk }\end{array}$ & $\begin{array}{c}2.48^{* * *} \\
(1.97-3.13)\end{array}$ & $\begin{array}{c}1.40 \\
(0.86-2.29)\end{array}$ & $\begin{array}{c}4.18^{* * *} \\
(2.88-6.06)\end{array}$ & $\begin{array}{c}3.16^{* * *} \\
(2.08-4.81)\end{array}$ & $\begin{array}{c}6.20^{* * *} \\
(3.58-10.73)\end{array}$ & $\begin{array}{c}4.79^{* * *} \\
(3.62-6.32)\end{array}$ & $\begin{array}{c}1.75^{* *} \\
(1.27-2.40)\end{array}$ \\
\hline
\end{tabular}

${ }^{*} \mathrm{p}<0.05 ;{ }^{* *} \mathrm{p}<0.01,{ }^{* * *} \mathrm{p}<0.001$

A MHS: Mental Health Specialty; GMS: General Medical Services; HS: Human Services; CAM: Complimentary Alternative Medicine; JJ: Juvenile Justice; ScS: School Services; Med: medication 
Table 3

Clinical Disorders predicted by Trauma Class

\begin{tabular}{|c|c|c|c|c|c|c|}
\hline Clinical Disorders ${ }^{\mathrm{A}}$ & Alcohol Abuse & Drug Abuse & Dysthymia & $\begin{array}{c}\text { Generalized } \\
\text { Anxiety } \\
\text { Disorder }\end{array}$ & $\begin{array}{l}\text { Major Depressive } \\
\text { Episode }\end{array}$ & PTSD \\
\hline Trauma Class & $\begin{array}{c}\text { OR } \\
(95 \% \mathrm{CI}) \\
\end{array}$ & $\begin{array}{c}\mathrm{OR} \\
(95 \% \mathrm{CI}) \\
\end{array}$ & $\begin{array}{c}\mathrm{OR} \\
(95 \% \mathrm{CI}) \\
\end{array}$ & $\begin{array}{c}\text { OR } \\
(95 \% \mathrm{CI}) \\
\end{array}$ & $\begin{array}{c}\mathrm{OR} \\
(95 \% \mathrm{CI}) \\
\end{array}$ & $\begin{array}{c}\mathrm{OR} \\
(95 \% \mathrm{CI}) \\
\end{array}$ \\
\hline $\begin{array}{l}\text { Class1 } \\
\text { High risk }\end{array}$ & $\begin{array}{c}23.87 \\
(9.98-57.13)^{* * *}\end{array}$ & $\begin{array}{c}26.24 \\
(11.78-58.48)^{* * *}\end{array}$ & $\begin{array}{c}10.45 \\
(4.44-24.58)^{* * *}\end{array}$ & $\begin{array}{c}9.71 \\
(3.63-25.97)^{* * *}\end{array}$ & $\begin{array}{c}9.64 \\
(4.34-20.93)^{* * *}\end{array}$ & $\begin{array}{c}14.55 \\
(6.17-34.32)^{* * *}\end{array}$ \\
\hline $\begin{array}{l}\text { Class2 } \\
\text { Sexual assault risk }\end{array}$ & $\begin{array}{c}5.08 \\
(2.88-8.98)^{* * *}\end{array}$ & $\begin{array}{c}8.25 \\
(4.92-13.82)^{* * *}\end{array}$ & $\begin{array}{c}5.58 \\
(3.39-9.19)^{* * *}\end{array}$ & $\begin{array}{c}4.17 \\
(2.30-7.56)^{* * *}\end{array}$ & $\begin{array}{c}4.56 \\
(3.07-6.77)^{* * *}\end{array}$ & $\begin{array}{c}7.28 \\
(4.90-10.84)^{* *}\end{array}$ \\
\hline $\begin{array}{l}\text { Class3 } \\
\text { Non-sexual risk }\end{array}$ & $\begin{array}{c}4.76 \\
(3.37-6.73)^{* * *}\end{array}$ & $\begin{array}{c}4.68 \\
(3.47-6.33)^{* * *}\end{array}$ & $\begin{array}{c}3.05 \\
(2.03-4.57)^{* * *}\end{array}$ & $\begin{array}{c}1.85 \\
(1.03-3.33)^{*}\end{array}$ & $\begin{array}{c}1.72 \\
(1.36-2.16)^{* * *}\end{array}$ & $\begin{array}{c}1.88 \\
(1.27-2.79)^{* *}\end{array}$ \\
\hline
\end{tabular}

${ }^{\mathrm{A}}$ Lifetime Diagnoses

${ }^{*} \mathrm{p}<0.05 ;{ }^{* *} \mathrm{p}<0.01,{ }^{* * *} \mathrm{p}<0.001$ 


\section{Table 4}

Clinical Disorders predicted by Service Use

\begin{tabular}{|c|c|c|c|c|c|c|}
\hline $\begin{array}{l}\text { Clinical } \\
\text { Disorders }\end{array}$ & $\begin{array}{l}\text { Alcohol } \\
\text { Abuse }\end{array}$ & $\begin{array}{l}\text { Drug } \\
\text { Abuse }\end{array}$ & Dysthymia & $\begin{array}{c}\text { Generalized } \\
\text { Anxiety Disorder }\end{array}$ & $\begin{array}{l}\text { Major Depressive } \\
\text { Episode }\end{array}$ & PTSD \\
\hline Services ${ }^{\mathrm{B}}$ & $\begin{array}{c}\mathrm{OR} \\
(95 \% \mathrm{CI})\end{array}$ & $\begin{array}{c}\mathrm{OR} \\
(95 \% \mathrm{CI})\end{array}$ & $\begin{array}{c}\text { OR } \\
(95 \% \mathrm{CI})\end{array}$ & $\begin{array}{c}\mathrm{OR} \\
(95 \% \mathrm{CI})\end{array}$ & $\begin{array}{c}\text { OR } \\
(95 \% \mathrm{CI})\end{array}$ & $\begin{array}{c}\mathrm{OR} \\
(95 \% \mathrm{CI})\end{array}$ \\
\hline MHS & $\begin{array}{c}2.41^{* * *} \\
(1.69-3.44)\end{array}$ & $\begin{array}{c}3.07^{* * *} \\
(2.23-4.23)\end{array}$ & $\begin{array}{c}3.69^{* * *} \\
(2.14-6.37)\end{array}$ & $\begin{array}{c}2.96^{* * *} \\
(1.69-5.16)\end{array}$ & $\begin{array}{c}3.02^{* * *} \\
(2.32-3.95)\end{array}$ & $\begin{array}{c}4.94^{* * *} \\
(3.24-7.54)\end{array}$ \\
\hline GMS & $\begin{array}{c}2.24^{*} \\
(1.18-4.24)\end{array}$ & $\begin{array}{c}1.37 \\
(0.76-2.47)\end{array}$ & $\begin{array}{c}1.63 \\
(0.75-3.56)\end{array}$ & $\begin{array}{c}1.66 \\
(0.75-3.64)\end{array}$ & $\begin{array}{c}1.93^{* *} \\
(1.17-3.17)\end{array}$ & $\begin{array}{c}1.86^{*} \\
(1.00-3.46)\end{array}$ \\
\hline HS & $\begin{array}{c}1.28 \\
(0.79-2.08)\end{array}$ & $\begin{array}{c}1.41 \\
(0.84-2.35)\end{array}$ & $\begin{array}{c}2.93^{* * *} \\
(1.74-4.93)\end{array}$ & $\begin{array}{c}1.81 \\
\left(\begin{array}{ll}0.96 & -3.41\end{array}\right)\end{array}$ & $\begin{array}{c}3.23^{* * *} \\
(2.12-4.92)\end{array}$ & $\begin{array}{c}3.46^{* * *} \\
(2.07-5.78)\end{array}$ \\
\hline CAM & $\begin{array}{c}1.96^{* *} \\
(1.19-3.23)\end{array}$ & $\begin{array}{c}1.66^{*} \\
(1.03-2.67)\end{array}$ & $\begin{array}{c}1.51 \\
(0.82-2.79)\end{array}$ & $\begin{array}{c}2.11^{*} \\
(1.10-4.04)\end{array}$ & $\begin{array}{c}1.97^{* *} \\
(1.26-3.06)\end{array}$ & $\begin{array}{c}2.00^{*} \\
(1.10-3.62)\end{array}$ \\
\hline $\mathrm{JJ}$ & $\begin{array}{c}5.35^{* * *} \\
(2.77-10.35)\end{array}$ & $\begin{array}{c}7.40^{* * *} \\
(4.15-13.21)\end{array}$ & $\begin{array}{c}1.07 \\
(0.44-2.57)\end{array}$ & $\begin{array}{c}0.39 \\
(0.13-1.16)\end{array}$ & $\begin{array}{c}0.65 \\
(0.30-1.42)\end{array}$ & $\begin{array}{c}1.31 \\
(0.40-4.29)\end{array}$ \\
\hline $\mathrm{ScS}$ & $\begin{array}{c}1.73^{*} \\
(1.11-2.72)\end{array}$ & $\begin{array}{c}1.95^{* *} \\
(1.30-2.92)\end{array}$ & $\begin{array}{c}1.40 \\
(0.70-2.80)\end{array}$ & $\begin{array}{c}1.18 \\
(0.55-2.49)\end{array}$ & $\begin{array}{c}1.63^{* *} \\
(1.14-2.32)\end{array}$ & $\begin{array}{c}1.01 \\
(0.57-1.79)\end{array}$ \\
\hline Med & $\begin{array}{c}0.81 \\
(0.48-1.34)\end{array}$ & $\begin{array}{c}1.21 \\
(0.72-2.02)\end{array}$ & $\begin{array}{c}1.82^{*} \\
(1.02-3.23)\end{array}$ & $\begin{array}{c}1.20 \\
(0.64-2.25)\end{array}$ & $\begin{array}{c}1.36 \\
(0.92-2.02)\end{array}$ & $\begin{array}{c}1.10 \\
(0.64-1.90)\end{array}$ \\
\hline
\end{tabular}

${ }^{\text {A }}$ Lifetime Diagnoses

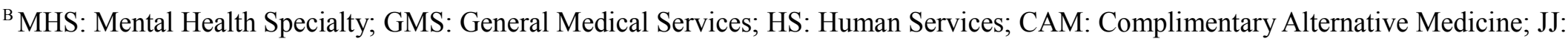
Juvenile Justice; ScS: School Services; Med: medication

${ }^{*} \mathrm{p}<0.05 ;{ }^{* *} \mathrm{p}<0.01,{ }^{* * *} \mathrm{p}<0.001$ 